\title{
Drug safety of rosiglitazone and pioglitazone in France: a study using the French PharmacoVigilance database
}

\author{
Stephanie Berthet ${ }^{1}$, Pascale Olivier ${ }^{1,2}$, Jean-Louis Montastruc ${ }^{1,2}$ and Maryse Lapeyre-Mestre ${ }^{1,2^{*}}$
}

\begin{abstract}
Background: Thiazolidinediones (TZDs), rosiglitazone (RGZ) and pioglitazone (PGZ) are widely used as hypoglycemic drugs in patients with type 2 diabetes mellitus. The aim of our study was to investigate the profile of adverse drug reactions (ADRs) related to TZDs and to investigate potential risk factors of these ADRs.

Methods: Type 2 diabetic patients were identified from the French Database of PharmacoVigilance (FPVD) between 2002 and 2006. We investigated ADR related to TZD, focusing on 4 ADR: edema, heart failure, myocardial infarction and hepatitis corresponding to specific WHO-ART terms.

Results: Among a total of 99,284 adult patients in the FPVD, 2295 reports concerned type 2 diabetic patients (2.3\% of the whole database), with 161 (7\%) exposed to TZDs. The frequency of edema and cardiac failure was significantly higher with TZDs than in other patients ( $18 \%$ and $7.4 \%$ versus $0.8 \%$ and $0.1 \%$ respectively, $p<0.001$ ) whereas the frequency of hepatitis was similar (5.9\% versus 4\%, NS). A multiple logistic regression model taking into account potential confounding factors (age, gender, drug exposure and co-morbidities) found that TZD exposure remained associated with heart failure and edema, but not with hepatitis or myocardial infarction.

Conclusions: Thiazolidinediones exposure is associated with an increased risk of edema and heart failure in patients with type 2 diabetes even when recommendations for use are respected. In contrast, the risk of hepatic reactions and myocardial infarction with this class of drugs seems to be similar to other hypoglycemic agents.
\end{abstract}

\section{Background}

Thiazolidinediones (TZDs) are peroxisome proliferatoractivated receptor (PPAR) agonists which regulate transcription of genes encoding proteins involved in glucose and lipid metabolism. Troglitazone, the first agent of this class, caused serious liver toxicity leading to its withdrawal in 2000, less than 3 years after its marketing [1]. The use of the 2 other TZDs, rosiglitazone (RGZ) and pioglitazone (PGZ), has sharply increased during the last few years. These 2 drugs seem to present a lower risk of hepatotoxicity than troglitazone [2].

TZDs could also induce adverse drug reactions (ADRs) related to the cardiovascular system including edema and heart failure $[3,4]$. Edema is more frequent when the TZD is used in combination therapy and its

\footnotetext{
* Correspondence: lapeyre@cict.fr

'Unité INSERM 1027, Equipe de Pharmacoépidémiologie, Université de

Toulouse (Université Paul Sabatier), Toulouse, France Full list of author information is available at the end of the article
}

incidence is higher in association with insulin. [4]. Because of the risk of congestive heart failure [5], the use of RGZ and PGZ was initially contraindicated in France in patients with a cardiac insufficiency corresponding to classes I to IV of the NYHA classification. The European Medicines Agency recommended the suspension of marketing authorizations for rosiglitazonecontaining anti-diabetes medicines in Europe in September 2010 [6]. This decision followed the publication of 2 studies finding an increased cardiovascular risk of rosiglitazone $[7,8]$. In view of the restrictions already in place on the use of rosiglitazone in Europe, no additional measures have been identified that could reduce this cardiovascular risk.

The aim of our study was to investigate the profile of adverse drug reactions (ADRs) related to TZDs as reported to the French PharmacoVigilance System in type 2 diabetic patients, with a special focus on congestive
C Biomed Central 
heart failure and myocardial infarction, and to investigate factors associated with these ADRs.

\section{Methods}

We used the data from the French national system of PharmacoVigilance, which has been described before $[9,10]$. All suspected ADRs are evaluated using a French standardized scale of causality assessment and registered in the French PharmacoVigilance Database (FPVD) [11]. For each report, information on patient's data (age, gender, medical history) and drug exposure (suspected and concomitantly used drugs) is recorded along with a brief clinical description. ADRs are coded according to ADR Terminology of the World Health Organization (WHO-ART) [12].

RGZ was the first TZD marketed at the end of 2001 in France. Therefore we performed searches in the French PharmacoVigilance Database for ADRs reported from January 2002 to December 2006. Among all cases of ADRs reported in the database, patients exposed to drugs approved in the treatment of diabetes in France were short-listed, and we selected only patients with type 2 diabetes. The following data were collected: age, gender, medical history (coded ICD $10^{\text {th }}$ ), and all drugs (coded according to the ATC classification) used, whether or not they were related to the present ADR. Several co morbidities were identified from medical history and use of drugs. The ADR were described according to the WHO-ART classification and presented as SOC terms. Several WHO-ART codes were retained to specifically describe edema (SOC term cardiovascular disorders and metabolic and nutritional disorders: edema, peripheral edema, low limbs edema), heart failure (SOC term cardiovascular disorders: cardiac failure, congestive cardiac failure, pulmonary edema), myocardial infarction (SOC term cardiovascular disorders and myocardia : myocardial infarction, cardiac death), and hepatitis (SOC term Liver and biliary system disorders: abnormal hepatic functions, abnormal ASAT-ALAT values, hepatitis).

The demographic and clinical characteristics of diabetic patients exposed and non-exposed to TZDs were compared using the $\chi 2$ test or Fisher's exact test for qualitative variables and using the Student's t-test for quantitative variables. In a further step, association between use of TZDs and occurrence of edema, hepatitis, cardiac failure or myocardial infarction was examined in a bivariate analysis. In order to take into account potential confounding factors (age, gender, cardiovascular comorbidities and other drugs), a multivariate analysis was performed using a backward logistic regression model. The Hosmer and Lemeshow procedure [13] was used to check the good fitting of the models. All analyses were done with the SAS $^{\circledR}$ software version 9.1.

\section{Results}

Out of 99,284 adult patients registered in the FPVD between January 2002 and December 2006, 2295 were patients with type 2 diabetes (2.3\% of the database). Table 1 presents the demographic and clinical characteristics of this population: half of the patients were men; the mean age was $67( \pm 13)$ years, they presented a high frequency of comorbidities, with $27.0 \%$ suffering from other metabolic disorders than diabetes, $25.9 \%$ with previous heart attack, and $10.8 \%$ with cardiac insufficiency. Half of the population was exposed to sulfamides, $40 \%$ to metformin and $5 \%$ was also treated with insulin. One hundred and sixty-one patients $(7 \%)$ were exposed to TZDs: $46.6 \%$ used pioglitazone, $44.7 \%$ used rosiglitazone, and $11.2 \%$ used roziglitazone + metformin (4 patients were exposed successively to rosiglitazone alone then to roziglitazone + metformin). These patients were younger, less frequently exposed to sulfamides and glinides, to statins and to NSAIDs than other diabetic patients. They presented less frequently cardiac insufficiency, but they were more frequently obese.

The number of reports containing ADRs related to TZDs increased from 2002 to the end of 2006, with 4 reports in 2002, 25 in 2003, 29 in 2004, 45 in 2005 and 58 in 2006 (Figure 1). Table 2 presents the most reported ADR which concerned "Body as a whole - general disorders", followed by "Metabolic and nutritional disorders", "Cardiovascular disorders" and "Skin and appendages disorders". Among the 5 ADRs related to sense disorders, 4 were macular edema, and there was no report of fractures. The degree of seriousness of reactions was similar whatever the groups, with $2.53 \%$ of ADR leading to death, $6.93 \%$ life-threatening, $0.61 \%$ leading to sequellae or disability, except for ADRs leading to hospitalization which were less frequent in TZD exposed patients (40.37\% versus $53.51 \%, \mathrm{p}<0.0001)$ and non-serious ADRs which were more frequent in TZD exposed patients (53.42\% versus $36.13 \%, \mathrm{p}<0.0001)$.

When considering specific ADR, heart failure was significantly more frequent in TZD patients ( 5 exposed to RGZ and 7 exposed to PGZ, 7.45\% versus $0.14 \%$ in nonexposed patients; $\mathrm{p}<0.001)$, as well as edema (9 exposed to RGZ and 20 to PGZ, $18.01 \%$ versus $0.84 \%$ in non-exposed patients; $\mathrm{p}<0.0001)$. We did not find any difference for hepatitis (4 patients exposed to RGZ and 4 to PGZ $4.97 \%$ versus $5.39 \%$ in non-exposed patients) and for myocardial infarction (only 1 case exposed to PGZ $0.62 \%$ versus $1.18 \%$ in non-exposed patients).

Table 3 presents the results of the multivariate analysis concerning the association between TZD exposure and 4 ADRs: heart failure, myocardial infarction, edema and hepatitis. Only edema and heart failure were significantly and independently associated with TZD respectively with 
Table 1 Demographic and clinical characteristics of patients identified in the French PharmacoVigilance Database with type 2 diabetes

\begin{tabular}{|c|c|c|c|}
\hline & $\begin{array}{l}\text { Total } \\
\text { population N } \\
=2295(\%)\end{array}$ & $\begin{array}{l}\text { TZD } \\
\text { exposed } N \\
=161(\%)\end{array}$ & $\begin{array}{l}\text { TZD not } \\
\text { exposed } N= \\
2134(\%)\end{array}$ \\
\hline Age (years) & $\begin{array}{l}67.2(13.4) \\
{[19-97]}\end{array}$ & $\begin{array}{l}63.3(14.2) \\
* * * * \\
{[32-87]}\end{array}$ & $\begin{array}{l}67.5(13.8) \\
{[19-97]}\end{array}$ \\
\hline Gender (men) & $1155(49.7)$ & $92(57.1)$ & $1063(49.8)$ \\
\hline \multicolumn{4}{|l|}{$\begin{array}{l}\text { Cardiovascular } \\
\text { comorbidities }\end{array}$} \\
\hline Cardiac arrhythmia & $128(5.58)$ & $8(5)$ & $120(5.6)$ \\
\hline Cardiac insufficiency & $248(10.81)$ & $9(5.6)^{*}$ & $239(11.2)$ \\
\hline Hypertension & $596(25.97)$ & $33(20.5)$ & $563(26.4)$ \\
\hline Metabolic disorders & $621(27.06)$ & $30(18.7)^{*}$ & $591(27.7)$ \\
\hline Angina pectoris & $154(6.71)$ & $6(3.7)$ & $148(6.9)$ \\
\hline Atherosclerosis & $6(0.26)$ & $0(0)$ & $6(0.28)$ \\
\hline Obesity & $76(3.31)$ & $10(6.2)^{*}$ & $66(3.1)$ \\
\hline Heart valve disorders & $7(0.31)$ & $1(0.6)$ & $6(0.28)$ \\
\hline Renal disorders & $62(2.7)$ & $2(1.2)$ & $60(2.8)$ \\
\hline \multicolumn{4}{|c|}{$\begin{array}{l}\text { Drugs used for type } 2 \\
\text { diabetes }\end{array}$} \\
\hline Sulfamides & $1227(53.46)$ & $\begin{array}{l}44(27.33) \\
* * * *\end{array}$ & $1183(55.43)$ \\
\hline $\begin{array}{l}\text { Alpha glucosidase } \\
\text { inhibitor }\end{array}$ & $207(9.02)$ & $4(2.48)^{* *}$ & $203(9.5)$ \\
\hline Glinides & $192(8.37)$ & $6(3.7)^{*}$ & $186(8.7)$ \\
\hline Metformin & $900(39.22)$ & $58(36)$ & $842(39.5)$ \\
\hline Benfluorex & $227(9.89)$ & $4(2.5)^{* *}$ & $223(10.45)$ \\
\hline Insulin & $115(5.01)$ & $4(2.94)$ & $111(5.20)$ \\
\hline \multicolumn{4}{|l|}{ Cardiovascular drugs } \\
\hline Diuretics & $627(27.32)$ & $34(21.1)$ & $593(27.7)$ \\
\hline ACE inhibitors & $456(19.87)$ & $20(12.4)^{*}$ & $436(20.4)$ \\
\hline Angiotensin II inhibitors & 339 (14.77) & $23(14.3)$ & $316(14.8)$ \\
\hline Digitalics & $105(4.58)$ & $3(1.9)$ & $102(4.8)$ \\
\hline Betablockers & $300(13.07)$ & $9(5.6)^{* *}$ & 291 (13.6) \\
\hline Calcium inhibitors & 321 (13.99) & 16 (9.94) & $305(14.3)$ \\
\hline Trinitrin & $48(2.09)$ & $3(1.9)$ & $45(2.1)$ \\
\hline Amiodarone & $103(4.49)$ & $2(1.24)^{*}$ & $101(4.73)$ \\
\hline $\begin{array}{l}\text { Central antihypertensive } \\
\text { drugs }\end{array}$ & $73(3.18)$ & $5(3.1)$ & $68(3.2)$ \\
\hline Antiarrythmia drugs & $25(1.09)$ & $1(0.6)$ & $24(1.12)$ \\
\hline \multicolumn{4}{|l|}{ Other drugs } \\
\hline $\begin{array}{l}\text { Steroidal and Non } \\
\text { Steroidal Anti- } \\
\text { Inflammatory Drugs }\end{array}$ & $232(10.1)$ & $8(4.96)^{*}$ & $224(10.5)$ \\
\hline Statins & $403(17.56)$ & $17(10.6)^{*}$ & $386(16.8)$ \\
\hline Fibrates & $142(6.19)$ & $7(4.35$ & $135(6.3)$ \\
\hline
\end{tabular}

$* p<0.05$.

$* * p<0.01$.

*** $\mathrm{p}<0.001$.

**** $\mathrm{p}<0.0001$

Quantitative variables are presented as mean (SD), [min-max] and qualitative variables as number (\%).

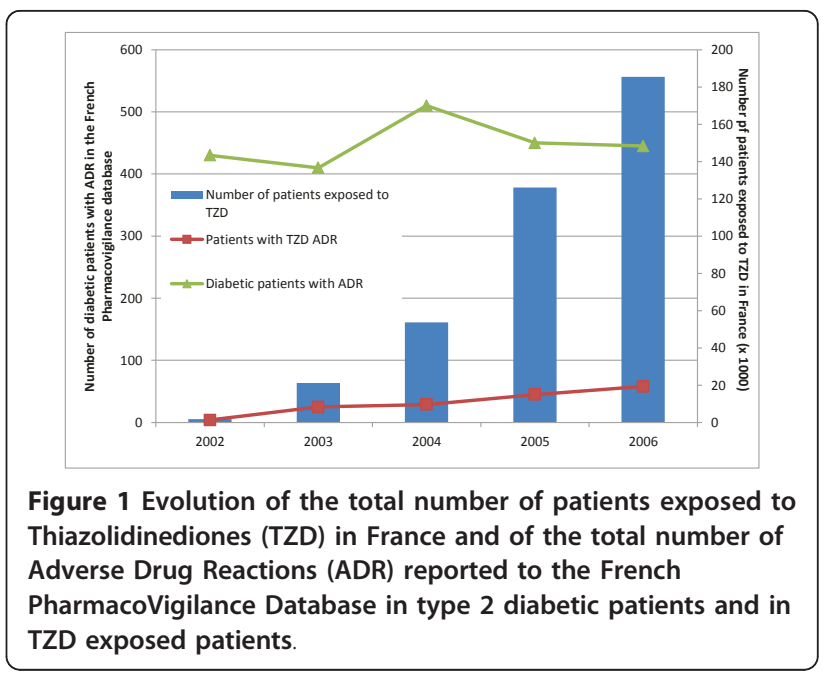

an OR of 25.09 and 65.39. Age and obesity were also associated with heart failure, and obesity with edema. Patients treated with biguanides were less exposed to risk of edema. We did not find any association between TZD and myocardial infarction (only heart

Table 2 Number and percentage of adverse drug reactions reported in the 161 patients exposed to thiazolidinediones in the French PharmacoVigilance database from 2002 to 2006

\begin{tabular}{ll}
\hline System Organ Classification terms & $\begin{array}{l}\text { Number of } \\
\text { patients (\%) }\end{array}$ \\
\hline Body as a whole - general disorders 1810 & $69(42.8)$ \\
Metabolic and nutritional disorders 0800 & $64(39.7)$ \\
Cardiovascular disorders, general 1010; Myo-, endo-, & $42(26.1)$ \\
pericardial \& valve disorders 1020; Heart rate and \\
rhythm disorders 1030 \\
Skin and appendages disorders 0100 \\
Central \& peripheral nervous system disorders 0410 \\
Red blood cell disorders 1210; White cell and & $35(21.7)$ \\
reticulo-endotelial system disorders 1220; Platelet, & $26(16.1)$ \\
bleeding \& clotting disorders 1230 & \\
Gastro-intestinal system disorders 0600 & $21(13.0)$ \\
Liver and biliary system disorders 0700 & $15(9.3)$ \\
Psychiatric disorders 0500 & $13(8.1)$ \\
Respiratory system disorders 1100 & $11(6.8)$ \\
Urinary system disorders 1300 & $7(4.3)$ \\
Vascular (extra-cardiac) disorders 1040 & $6(3.7)$ \\
Vision disorders 0431; Hearing and vestibular & $5(3.1)$ \\
disorders 0432; Special senses other, disorders 0433 & \\
Endocrine disorders 0900 & $4(2.5)$ \\
Immune system & $3(1.9)$ \\
Muscular-skeletal system disorders 0200 & $2(1.2)$ \\
Fetal disorders 1500 & $2(1.2)$ \\
\hline Total number of adverse drug reactions & 358 \\
\hline &
\end{tabular}


Table 3 Results of the multiple logistic regression models concerning the association between TZD exposure and 4 ADRs: Heart Failure, Myocardial Infarction, Edema and Hepatitis

\begin{tabular}{|c|c|c|c|}
\hline Heart failure & $\begin{array}{l}\text { Odds } \\
\text { ratio }\end{array}$ & $(95 \% \mathrm{Cl})$ & $P$ \\
\hline$\overline{\text { Age }}$ & 1.04 & $(0.99-1.09)$ & 0.0705 \\
\hline Obesity & 5.69 & $(1.34-24.20)$ & 0.0185 \\
\hline Thiazolidinediones & 65.39 & $(17.678-241.93)$ & $<0.0001$ \\
\hline \multicolumn{2}{|c|}{ Hosmer and Lemeshow procedure } & & 0.32 \\
\hline \multicolumn{4}{|l|}{ Myocardial infarction } \\
\hline$\overline{\text { Age }}$ & 0.97 & $(0.95-1.00)$ & 0.1076 \\
\hline Gender & 1.73 & $(0.78-3.84)$ & 0.1727 \\
\hline Thiazolidinediones & 0.42 & $(0.05-3.17)$ & 0.4039 \\
\hline Heart valve disorders & 25.95 & $(2.63-255.47)$ & 0.0053 \\
\hline Hypertension & 0.34 & $(0.09-1.19)$ & 0.0929 \\
\hline \multicolumn{2}{|c|}{ Hosmer and Lemeshow procedure } & & 0.8254 \\
\hline \multicolumn{4}{|l|}{ Edema } \\
\hline Obesity & 1.89 & $(0.58-6.17)$ & 0.2863 \\
\hline Thiazolidinediones & 25.09 & $(13.50-46.63)$ & $<0.0001$ \\
\hline Biguanides & 0.42 & $(0.20-0.87)$ & 0.02 \\
\hline \multicolumn{2}{|c|}{ Hosmer and Lemeshow procedure } & & 0.8043 \\
\hline \multicolumn{4}{|l|}{ Hepatitis } \\
\hline Age & 0.99 & $(0.97-1.00)$ & 0.1167 \\
\hline Angina pectoris & 0.43 & $(0.13-1.39)$ & 0.1620 \\
\hline Cardiac arrhythmia & 0.36 & $(0.08-1.52)$ & 0.1686 \\
\hline Cardiac insufficiency & 0.58 & $(0.25-1.37)$ & 0.2217 \\
\hline Thiazolidinediones & 0.84 & $(0.40-1.78)$ & 0.6645 \\
\hline $\begin{array}{l}\text { Non Steroidal Anti- } \\
\text { Inflammatory Drugs }\end{array}$ & 1.85 & $(1.13-3.01)$ & 0.0134 \\
\hline Diuretics & 0.58 & $(0.32-1.06)$ & 0.0796 \\
\hline Calcium inhibitors & 0.63 & $(0.32-1.23)$ & 0.1798 \\
\hline Angiotensin II inhibitors & 0.68 & $(0.35-1.32)$ & 0.2804 \\
\hline \multicolumn{2}{|c|}{ Hosmer and Lemeshow procedure } & & 0.4397 \\
\hline
\end{tabular}

Potential confounding factors retained in the final model are indicated in the first column.

valve disorders were significantly associated) or hepatitis (as expected, there was a significant association between hepatitis and NSAID).

\section{Discussion}

Among this population of diabetic patients registered in the French Pharmacovigilance database due to the occurrence of an adverse drug reaction, seven percent was exposed to TZDs. In these patients, the reactions were less frequently serious than in patients exposed to other antidiabetic agents. TZD exposure is associated with edema and heart failure in patients with type 2 diabetes, but the risk of hepatic reactions or myocardial infarction with this class of drugs is the same with other hypoglycemic agents.

TZDs can potentially lead to the development of congestive heart failure [1]. In clinical trials, the incidence of edema ranged from 2 to 5\% in TZD monotherapy, 6 to $8 \%$ with metformin or sulfonylurea and $15 \%$ in combination with insulin. In our study, edema represented $18 \%$ of ADR related to TZD, and concerned mainly patients exposed to PGZ. Fluid retention can occur even at the lowest TZD dose, and diuretics and ACE inhibitors have variable effects on edema caused by TZDs $[1,3]$.

We found only one case of myocardial infarction in a patient exposed to PGZ, and this event should not be related to this drug. It concerned a 46-year-old man, treated by lamivudine-zidovudine-nevirapine for a HIV infection, and presenting high serum levels of triglycerides $4,57 \mathrm{mmol} / \mathrm{l}(\mathrm{N}<1,74 \mathrm{mmol} / \mathrm{l})$, cholesterol 8,80 $\mathrm{mmol} / \mathrm{l}(\mathrm{N}<6,56 \mathrm{mmol} / \mathrm{l})$, with a normal value for HDL-cholesterol. He was also treated by glicazide and benfluorex. After one year of treatment with TGZ, he presented a myocardial infarction successfully treated by angioplasty and a drug-eluting stent. The treatment with PGZ was maintained with a favorable evolution. We did not found any other cases with RGZ or PGZ, whereas 26 myocardial infarctions potentially related to drugs were reported in the population of diabetic patients in this study. Two meta-analyses have suggested that RGZ increases the risk of myocardial infarction but did not reach statistical significance for cardiovascular death $[14,15]$, but the reviews published in 2010 led to the rosiglitazone withdrawal from the European market in September 2010. The final results of the RECORD trial, which compared cardiovascular outcomes in patients with type 2 diabetes treated with RGZ and metformin or sulfonylurea, confirm the increasing risk of heart failure with RGZ, but do not identify any statistically significant differences in the overall risk of cardiovascular morbidity or mortality [16]. Lincoff's meta-analysis on the effect of PGZ on ischemic cardiovascular events found that PGZ is associated with a significantly lower risk of death, myocardial infarction, or stroke [17]. In their review of the literature in order to estimate the association between hypoglycemic agents and morbidity and mortality in patients with heart failure and diabetes, Eurich et al [18] concluded that metformin is the only hypoglycemic agent not associated with harm in patients with heart failure. A nested case-control study in older patients found that both PGZ and RGZ were associated with an increased risk of congestive heart failure, acute myocardial infarction, and mortality when compared to other combinations of oral hypoglycemic agents [19].

Cases of hepatotoxicity with second generation TZDs have been few in number and less severe when compared to troglitazone $[2,20]$. Troglitazone, unlike PGZ and RGZ, induces the cytochrome P450 isoform 3A4, which is partly responsible for its metabolism, and may be prone to drug interactions. Floyd et al examined reports of liver failure reported to the FDA during 
10 years and estimated that the rate of acute liver failure observed with RGZ or PGZ was about 17 times higher than the background rate for idiopathic acute liver failure in the general population [21]. By contrast, in our study, we did not find any association between hepatitis and TZD in comparison with other drugs used for diabetes. Even if no reliable estimates of the background rate of liver failure in diabetic patients are available in the literature, some have postulated that liver disease may be more frequent in this population with obesity and insulin resistance, due to non-alcoholic steato-hepatitis [2]. Moreover, this population may be exposed to other drugs, some of which are suspected to increase the risk of hepatic injuries [22], as observed in our data with NSAID.

Some limitations of our study should be discussed. First, limitations are due to the spontaneous reporting system itself, although the reporting rate in France is one of the highest among the European countries $[23,24]$. Given the small number of patients treated by TZDs in France, the number of ADR reports with TZD is relatively low, in comparison with the results obtained through the Health Canada's spontaneous adverse event reporting system (195 ADR with pioglitazone and 830 with rosiglitazone up to September 2006) [25]. Underreporting can affect validity of results since it can be related either to the drug or to the degree of seriousness of reactions. We did not find any case of myocardial infarction or fracture related to TZD in the database. This is not surprising, since in any spontaneous reporting system, clinicians are unlikely to report this kind of event related to TZD, and instead attribute them to the baseline risk of type 2 diabetes. The absence of fractures reported to the French pharmacovigilance system does not mean that this risk is not real. As demonstrated in the meta-analysis of 10 randomized controlled trials and 2 observational studies, long-term use of TZD doubles the risk of fractures among women with type 2 diabetes, without a significant increase in the risk of fractures in diabetic men [26]. In our study, reported ADRs in the exposed population has increased year by year since the marketing authorization of TZDs in France. This increase can be explained by the increased use of TZDs but also biased by reports related to the notoriety of TZD ADRs. This last point is limited as reports with TZD seem to be less frequently serious than for other diabetic patients.

Populations of patients with specific disease identified through the FPVD are very similar to that obtained through population-based studies in France $[27,28]$. This population of type 2 diabetic patients with ADR related to their medications presents characteristics comparable to those observed in other studies about French type 2 diabetes [29-31]: for example, we found that $11 \%$ of the patients suffered from cardiac insufficiency, which is very similar to the $12 \%$ observed in the ENTRED national survey [30]. Moreover, the patterns of exposure to drugs in this population are in agreement with the guidelines for TZD use at the time of the study (in particular, TZDs are contraindicated with insulin and for patients with NYHA class I to IV). In our study, patients exposed to TZDs were less likely to present risk factors of heart failure and cardiovascular comorbidities, 5.6\% had a cardiac insufficiency, and less than $3 \%$ were treated concomitantly with insulin.

\section{Conclusions}

In the French Pharmacovigilance database, adverse drug reactions reported in diabetic patients exposed to thiazolidinediones (rosiglitazone and pioglitazone) present a degree of seriousness similar to that observed with other anti diabetic drugs. Thiazolidinediones exposure is associated with an increased risk of edema and heart failure in patients with type 2 diabetes even when recommendations for use are respected, and this risk concerns much rosiglitazone as pioglitazone. In contrast, the risk of hepatic reactions and myocardial infarction, which has been discussed with this class of drugs, is not higher than with other hypoglycemic agents.

\section{Acknowledgements}

The authors acknowledge the assistance of all 31 regional centres of the French Pharmacovigilance System through the "Association Française des Centres Régionaux de Pharmacovigilance" (AFCRPV).

The authors acknowledge Ms. Pascale Morandi for editing the manuscript.

\section{Author details}

'Unité INSERM 1027, Equipe de Pharmacoépidémiologie, Université de Toulouse (Université Paul Sabatier), Toulouse, France. ${ }^{2}$ Centre Régional de Pharmacovigilance, de Pharmacoépidémiologie et d'Information sur le Médicament, Service de Pharmacologie Clinique, Hôpitaux de Toulouse, Toulouse, France.

\section{Authors' contributions}

PO and MLM planed the study, SB managed the data, performed the statistical analysis and wrote the main results, JLM and MLM wrote the final manuscript. JLM is the head of the regional pharmacovigilance center and gave his support to access the French pharmacovigilance database. All authors read and approved the final manuscript.

\section{Competing interests}

None of the authors have any relevant conflict of interest.

SB received a grant from the "Fondation de France" to perform this study during her Master Research training in Clinical Epidemiology (University of Toulouse).

Received: 7 September 2010 Accepted: 24 May 2011

Published: 24 May 2011

\section{References}

1. CV Rizos, MS Elisaf, DP Mikhailidis, EN Liberopoulos, How safe is the use of thiazolidinediones in clinical practice. Expert Opin Drug Saf. 8, 15-32 (2009). doi:10.1517/14740330802597821

2. AJ Scheen, Hepatotoxicity with thiazolidinediones: is it a class effect? Drug Saf. 24, 873-88 (2001). doi:10.2165/00002018-200124120-00002 
3. NV Niemeyer, LM Janney, Thiazolidinedione-induced edema. Pharmacotherapy. 22, 924-9 (2002). doi:10.1592/phco.22.11.924.33626

4. TE Delea, JS Edelsberg, M Hagiwara, G Oster, LS Phillips, Use of thiazolidinediones and risk of heart failure in people with type 2 diabetes: a retrospective cohort study. Diabetes Care. 26, 2983-9 (2003). doi:10.2337/ diacare.26.11.2983

5. P Raskin, M Rendell, MC Riddle, JF Dole, MI Freed, J Rosenstock, A randomized trial of rosiglitazone therapy in patients with inadequaly controlled insulin-treated type2 diabetes. Diabetes Care. 24, :1226-32 (2001). doi:10.2337/diacare.24.7.1226

6. European Medicines Agency, European Medicines Agency recommends suspension of Avandia, Avandamet and Avaglim. Anti-diabetes medication to be taken off the market. http://www.ema.europa.eu/docs/en_GB/ document_library/Press_release/2010/09/WC500096996.pdf (2010). EMA/ 585784/2010 (accessed on May 17, 2011)

7. DJ Graham, R Ouellet-Hellstrom, TE MaCurdy, F Ali, C Sholley, C Worrall, JA Kelman, Risk of acute myocardial infarction, stroke, heart failure, and death in elderly Medicare patients treated with rosiglitazone or pioglitazone. JAMA. 304, 411-8 (2010). doi:10.1001/jama.2010.920

8. SE Nissen, K Wolski, Rosiglitazone revisited. An updated meta analysis of risk for myocardial infarction and cardiovascular mortality. Arch Intern Med. 170, 1191-1201 (2010). doi:10.1001/archinternmed.2010.207

9. F Thiessard, E Roux, G Miremont-Salame, A Fourrier-Reglat, F Haramburu, P Tubert-Bitter, B Begaud, Trends in spontaneous adverse drug reaction reports to the French PharmacoVigilance system (1986-2001). Drug Saf. 28 731-740 (2005). doi:10.2165/00002018-200528080-00007

10. IR Edwards, JK Aronson, Adverse drug reactions: definitions, diagnosis, and management. Lancet. 356, 1255-1259 (2000). doi:10.1016/S0140-6736(00) 02799-9

11. B Begaud, JC Evreux, J Jouglard, G Lagier, Imputation of the unexpected or toxic effects of drugs. Actualization of the method used in France. Therapie. 40, 111-118 (1985)

12. $\mathrm{WHO}$ collaborating Center for International Drug monitoring, WHO International monitoring of adverse reactions to drugs: adverse reaction terminology Uppsala. (2011)

13. S Lemeshow, DW Hosmer, A review of goodness of fit statistics for use in the development of logistic regression models. Am J Epidemiol. 115, 92-106 (1982)

14. SE Nissen, K Wolski, Effect of rosiglitazone on the risk of myocardial infarction and death from cardiovascular causes. N Engl J Med. 356 2457-71 (2007). doi:10.1056/NEJMoa072761

15. S Singh, YK Loke, CD Furberg, Long-term risk of cardiovascular events with rosiglitazone: a meta-analysis. JAMA. 298, 1189-95 (2007). doi:10.1001/ jama.298.10.1189

16. PD Home, SJ Pocock, H Beck-Nielsen, PS Curtis, R Gomis, M Hanefeld, NP Jones, M Komadja, JJV McMurray, for the RECORD Study Group, Rosiglitazone evaluated for cardiovascular outcomes in oral combination therapy for type 2 diabetes (RECORD): a multicentre, randomized, openlabel trial. Lancet. 373, 2125-35 (2009). doi:10.1016/S0140-6736(09)60953-3

17. AM Lincoff, K Wolski, SJ Nicholls, SE Nissen, Pioglitazone and risk of cardiovascular events in patients with type 2 diabetes mellitus: a metaanalysis of randomized trials. JAMA. 298, 1180-8 (2007). doi:10.1001/ jama.298.10.1180

18. DT Eurich, FA McAlister, DF Blackburn, SR Majumdar, RT Tsuyuki, J Varney, JA Johnson, Benefits and harms of antidiabetic agents in patients with diabetes and heart failure: systematic review. BMJ. 335, 497 (2007). doi:10.1136/bmj.39314.620174.80

19. LL Lipscombe, T Gomes, LE Lévesque, JE Hux, DN Juurlink, DA Alter, Thiazolidinediones and cardiovascular outcomes in older patients with diabetes. JAMA. 298, 2634-43 (2007). doi:10.1001/jama.298.22.2634

20. R Rajagopalan, S Iyer, A Perez, Comparison of pioglitazone with other antidiabetic drugs for associated incidence of liver failure: no evidence of increased risk of liver failure with pioglitazone. Diabetes Obes Metab. 7, 161-9 (2005). doi:10.1111/j.1463-1326.2004.00382.x

21. JS Floyd, E Barbehenn, P Lurie, SM Wolfe, Case series of liver failure associated with rosiglitazone and pioglitazone. Pharmacoepidemiol Drug Saf. 18, 1238-43 (2009). doi:10.1002/pds.1804

22. M Lapeyre-Mestre, AM de Castro, MP Bareille, JG Del Pozo, AA Requejo, LM Arias, JL Montastruc, A Carvajal, Non-steroidal anti-inflammatory drugrelated hepatic damage in France and Spain: analysis from national spontaneous reporting systems. Fundam Clin Pharmacol. 20, 391-5 (2006) doi:10.1111/j.1472-8206.2006.00416.x

23. B Bégaud, K Martin, F Haramburu, N Moore, Rates of spontaneous reporting of adverse drug reactions in France. JAMA. 288, 1588 (2002). doi:10.1001/ jama.288.13.1588

24. KJ Belton, Attitude survey of adverse drug-reaction reporting by health care professionals across the European Union. Eur J Clin Pharmacol. 52, 423-427 (1997). doi:10.1007/s002280050314

25. S Singh, YK Loke, CD Furberg, Thiazolidinediones and heart failure. A teleoanalysis. Diabetes Care. 30, 2148-2153 (2007). doi:10.2337/dc07-0141

26. YK Loke, S Singh, CD Furberg, Long-term use of thiazolidinediones and fractures in type 2 diabetes: a meta-analysis. CMAJ. 180, 32-9 (2009)

27. M Gony, M Lapeyre-Mestre, JL Montastruc, Risk of serious extrapyramidal symptoms in patients with Parkinson's disease receiving antidepressant drugs : a pharmacoepidemiologic study comparing serotonin reuptake inhibitors and other antidepressant drugs. Clin Neuropharmacol. 26, 142-5 (2003). doi:10.1097/00002826-200305000-00007

28. S Berthet, S Grolleau, C Brefel-Courbon, JL Montastruc, M Lapeyre-Mestre, Prevalence of Diabetes in France and Drug Use: Study Based on the French PharmacoVigilance Database. Therapie. 62, 483-488 (2007). doi:10.2515/ therapie:2007076

29. C Marant, I Romon, S Fosse, A Weill, D Simon, E Eschwège, M Varroud-Vial, A Fagot-Campagna, French medical practice in type 2 diabetes: the need for better control of cardiovascular risk factors. Diabetes Metab. 34, 38-45 (2008)

30. Institut de Veille Sanitaire, Le diabète. Echantillon national témoin représentatif des personnes diabétiques (Entred) 2007-2010.

31. http://www.invs.sante.fr/surveillance/diabete/entred_2007_2010/index.html. (accessed on May 17, 2011)

32. Agence Nationale d'Accréditation et d'Evaluation en Santé, Principes de dépistage du diabète de type 2. Paris : ANAES. (2003)

\section{Pre-publication history}

The pre-publication history for this paper can be accessed here: http://www.biomedcentral.com/1472-6904/11/5/prepub

doi:10.1186/1472-6904-11-5

Cite this article as: Berthet et al:: Drug safety of rosiglitazone and pioglitazone in France: a study using the French PharmacoVigilance database. BMC Clinical Pharmacology 2011 11:5.

\section{Submit your next manuscript to BioMed Central and take full advantage of:}

- Convenient online submission

- Thorough peer review

- No space constraints or color figure charges

- Immediate publication on acceptance

- Inclusion in PubMed, CAS, Scopus and Google Scholar

- Research which is freely available for redistribution

Submit your manuscript at www.biomedcentral.com/submit
C Biomed Central 